\title{
Assessment of Noise from Transportation Systems in Ilorin, Nigeria
}

\author{
S. O. Bilewu ${ }^{1}$, A. W. Salami ${ }^{1}$, A. M. Ayanshola ${ }^{1}$, I. T Yusuf ${ }^{2}$ \\ ${ }^{1}$ Department of Water Resources and Environmental Engineering, University of Ilorin, Nigeria. \\ ${ }^{2}$ Department of Civil Engineering, University of Ilorin, Ilorin, Nigeria.
}

\begin{abstract}
Noise from transportation systems is unavoidable in urban areas and can be harmful to human health. The noise generated by selected transportations systems in Ilorin, an urban area in central Nigeria, was studied by direct measurements and the use of questionnaires. Measurements were taken at the airport, train station and different locations for vehicular traffic. Questionnaires were also administered on residents of these areas to elicit information on the perception of transportation noise in the areas. The results show that all the studied locations produced maximum noise levels in excess of the 85-dBA acceptable tolerable limit for humans. The train station produced the highest stepwise noise levels due to the motion and horning of the locomotive engines. The study also established distances in which the sound level is safe over a specific period of time for each of the studied noise sources. These are of $18.84 \mathrm{~m}, 161.21 \mathrm{~m}, 13.85 \mathrm{~m}$ and $15.08 \mathrm{~m}$ for aircraft take-off, movement and horning of railway locomotive engine and vehicular traffic inside and outside town respectively. Suggested solutions were that residential buildings, academic areas and hospitals should not be located too close to sources of transportation noise and the need for enforcement of relevant noise control laws is to be pursued.
\end{abstract}

KEYWORDS: Noise pollution, sound pressure level, equivalent sound level, acceptable noise level, noise perception.

[Received May 16, 2018; Revised October 30, 2018; Accepted March 01, 2019]

Print ISSN: 0189-9546 | Online ISSN: 2437-2110

\section{INTRODUCTION}

Noise pollution is a by-product of urbanization and industrialization and is now worldwide recognized as a major problem affecting the quality of life in urban areas. Though considered less severe than other environmental challenges, the continuous increase in urban population and in the number of means of transportation have led to regular increase in noise pollution in urban areas. (Mansouri et al., 2006). However, the leadingsource of noise in many cities of the world is the traffic or road noise (Yilmaz and Ozer, 2005). Aircraft and rail noise are acoustically characterized by high noise levels of relative short duration (Omubo-Pepple et al., 2010) and increasing noise of airport and motorway traffic in the city centers have become a part of modern life (Obisung et al, 2013).

Another important source of urban noise is the rail systems (Gershon et al, 2006). As an example, a rail car retarder can produce a high frequency, high level screech that can reach as high as $140 \mathrm{~dB}$ at a distance of 30m (Abolarin, 2012). Sound waves travel from source to receiver through a variety of media. Outdoors, it will be through the atmosphere and will then be influenced by wind turbulence and gradients, air temperature, ground reflections, etc. The amplitude, the spectrum as well as the duration of the sound will also be affected.

Noise pollution continues to grow in cities in contrast to many other environmental problems such as air pollution and is accompanied by an increasing number of complaints from people exposed to it. This increase is unsustainable as it leads

*Corresponding author: bilewuk@yahoo.com m to direct and cumulative adverse health sociocultural, aesthetic and economic effects. (Yilmaz and Ozer, 2005; Ko et al, 2011; Aremu et al, 2012; Pathak, 2007; Pandya, 2003). Areas located less than $200 \mathrm{~m}$ from the center of a highway have been shown to have a high concentration of air pollutants and road traffic noise levels, creating substantial impacts on the health and well-being of the people living there (Carrier et al, 2016).

There are legal provisions relating to noise control in Nigeria. The National Environmental (Noise Standards and Control) Regulations was gazetted by the Federal Government of Nigeria in October 2009. It prescribes the maximum permissible noise levels of facilities and activities to which a person may be exposed and provides noise control and mitigating measures for the reduction of noise.

There are also standards for maximum permissible noise levels (continuous, intermittent or impulsive noise) from a factory or workshop, construction sites, public announcement systems or device, places of entertainment, places and areas of worship and from mines and quarries.

The noise pollution situation in Ilorin metropolis is similar to that in many other urban areas. These areas are being subjected to persistent road traffic and commercial activities due to overall increase in prosperity, fast rate of development, and expansion of the economy (Oyedepo \& Saadu, 2010). Very few studies have been carried out to investigate and assess noise pollution in Ilorin metropolis.

The human ear responds to changes in sound pressure in a relative rather than absolute manner and thus a logarithmic 


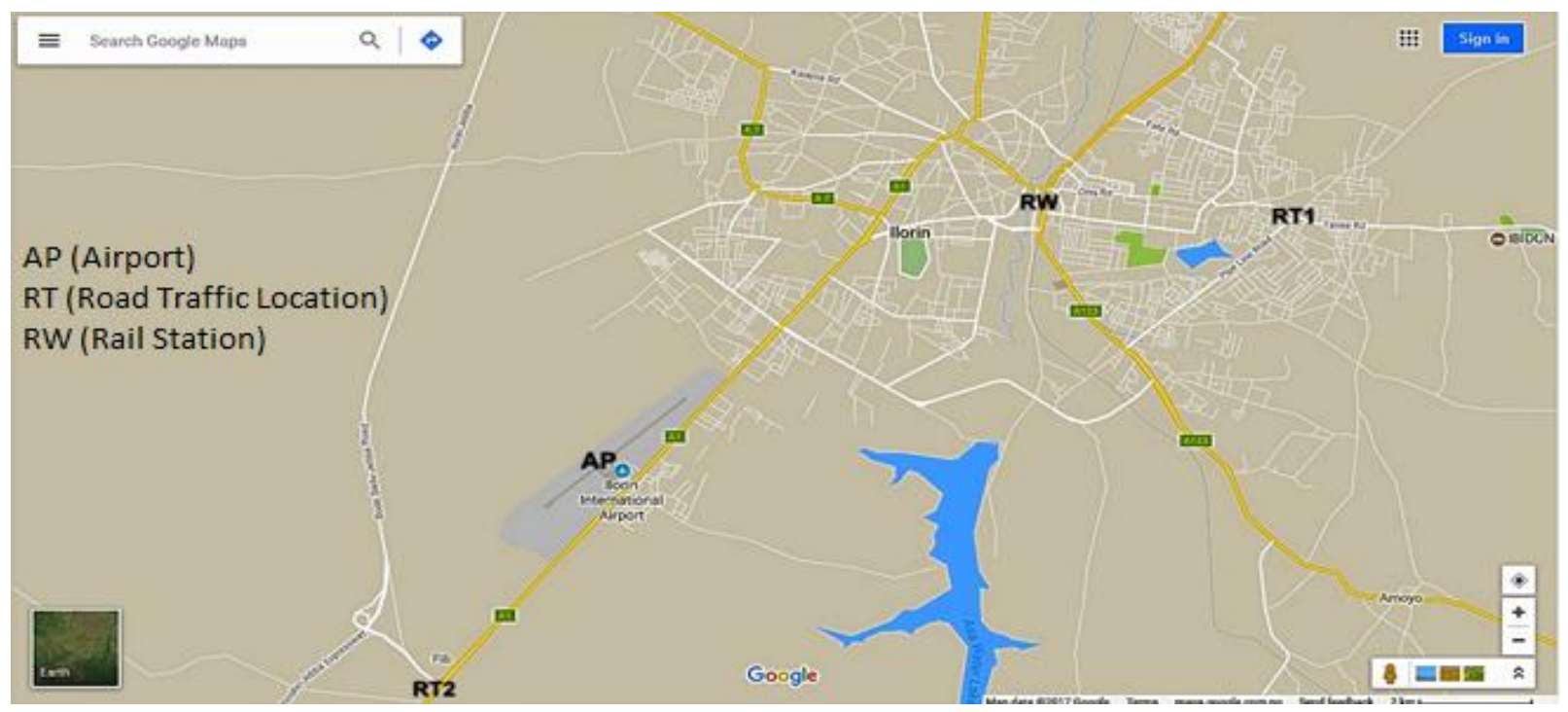

Figure 1: Map of Ilorin showing the major transportation routes and sampling locations.

scale, the decibel $(\mathrm{dB})$, is used to measure sound pressure level. Acceptable tolerable noise is $85 \mathrm{~dB}$, (OSHA, 1996). The weakest sound that the human ear can detect is referred to as the threshold of hearing and it corresponds to $0 \mathrm{~dB}$ while the level of sound pressure that will cause pain to the ear is referred to as the threshold of pain. This corresponds to $120 \mathrm{~dB}$ (Defra, 2010). Any sound which is annoying or level of sound exceeds $75 \mathrm{~dB}$ (A) may be conceived as noise. The threshold for noise annoyance varies. It depends on the conditions, including the sensitivity and mental state of an individual (Luqman et al, 2014).

According to the National Environmental Standards and Regulation Enforcement Agency (NESREA) in Nigeria, noise is now a criminal offence punishable by imprisonment or fine or both. The World Health Origination (WHO) recommends a maximum permissible noise limit of $90 \mathrm{~dB}$ (Anomohanran et al., 2013).

Annoyance is the most reported problem caused by transport noise exposure and is often the primary outcome used to evaluate the effect of noise on communities. Acoustic factors such as noise source, exposure level and time of day of exposure only partly determine an individual's annoyance response (Clark \& Stansfeld, 2007). Saadu et al (1996), in a survey, ranked road traffic noise only second to radio and loudspeakers as the greatest source of annoyance. It is also reported that the degree of noise annoyance depends on traffic mode. At the same average noise level, the percentage of highly annoyed resident's decreases in the order aircraft noise, road traffic noise, and rail traffic noise (Basner et al, 2011). This study therefore seeks to assess the noise intensity levels and its perception from different transportation systems within the Ilorin metropolis.

\section{THE STUDY AREA}

Ilorin is located on latitude $8^{\circ} 24^{\prime} 0^{\prime \prime} \mathrm{N}$ and $8^{\circ} 36^{\prime} 00^{\prime \prime} \mathrm{N}$ and longitude $4^{\circ} 10^{\prime} 00^{\prime \prime} \mathrm{E}$ and $4^{\circ} 36^{\prime \prime} 00 \mathrm{E}$ and covers an area of about $100 \mathrm{~km}^{2}$ (Ajadi et al., 2011). The 2006 census had its population at 777,667 (NPC, 2006). This would be 905,774 by the year 2019 if the annual growth rate remains at $1.4 \%$. It is situated at a strategic point between the densely populated south-western and the sparsely populated middle belt of Nigeria. (Ajadi et al., 2011). Despite its strategic location as the gateway between the southern and northern parts of the country, there are few industries in Kwara State. Ilorin has a good network of roads, rail and air transportation facilities linking it with Nigeria's other industrial and commercial centers in Nigeria. This study is based on the results of outdoor sound level measurements obtained from the various locations as follows;

\section{A. Major road within the Ilorin metropolis}

The area chosen for data gathering within the town is the Tipper Garage area (RT1 in Figure 1), which enjoys the convergence of all types of vehicles. There is constant traffic delays in this area. Eiyenkorin Road (RT2 in Figure 1) is also chosen to measure outbound traffic noise. Vehicles in the area experience less traffic delays.

\section{B. Ilorin International Airport}

Ilorin International Airport, marked as AP in Figure 1, serves the town. The Ilorin non-directional beacon is located on the field. The airport is on a latitude and longitude of $8.440211 \mathrm{~N}$ and $4.493919 \mathrm{E}$ at an elevation of 1126 feet (343 metres above sea level, masl) and runway surface is made of asphalt. This study measured the noise from domestic flight aircrafts during takeoff and landing and also during 'No flight' periods.

One of the operational aircrafts that frequents the airport is the ATR 42. This is a twin-turboprop, short-haul regional airliner built in France and Italy. ATR aircraft models share resources and technology with Airbus. ATR aircraft meets both external noise and gaseous emission level regulatory requirements with ample margins. 


\section{Ilorin Railway station}

The Railway station, marked as RW in Figure 1, is at the centre of the town. It has served as a major catalyst to the socio-economic development of the town, therefore, the noise level readings was taken at the railway station.

\section{METHODOLOGY}

In carrying out the noise level measurements, strategic locations were carefully selected for this study. The measurement of the sound level was carried out using an Extech HD600 model Digital Sound Level Meter. It measures and displays sound pressure levels in decibels ranging from $30 \mathrm{~dB}$ (A) to130 dB (A) which makes it suitable for environmental noise survey.

The sound pressure level is a commonly used measure for the magnitude of sound. Typical average sound pressure levels range from about $20 \mathrm{dBA}$ in a quiet rural area at night to between 50 and $70 \mathrm{dBA}$ in towns during the daytime, to 90 $\mathrm{dBA}$ or more in noisy factories and discotheques, to well over $120 \mathrm{dBA}$ near a jet aircraft at take-off (Mayer, 2018).

The data accumulation exercise was undertaken to obtain the results of outdoor sound level measurements using the sound level meter at a safe distance from the noise source with the help of prepared research collaborators. All readings were taken at a favourable weather condition. Questionnaires were also administered to the respondents and collected instantly after being completed.

The air noise measurements taken for three days during landing and taking off of the aircrafts (ATR 42 propeller aircraft) were made at the Ilorin International Airport after assessment and clearance was granted by the Federal Airports Authority of Nigeria (FAAN). Preliminary survey was conducted to obtain flight schedules and types of aircrafts usually received at the airport. Based on these, a decision was taken to consider the Overland Airways propeller ATR-42 Aircraft for the study. The regularity and the itinerary of movement of this flight was also a factor in the choice. Other aircrafts that use the airport include military aircrafts, Choppers, Boeing 737 - series 2-500 and bombardier-built crafts.

To take records, a safe boundary was assigned close to the runway by FAAN officials and the Sound Level Meter (SLM) was usually set up minutes before landing of the aircraft and supervised by an aviation Duty Officer. The reference axis of the SLM was parallel to the ground and made at an angle of $45^{\circ}$ with the vertical plane containing the direction of the noise source as is standard practice (Plate 1). The microphone height above the ground was $1.2 \mathrm{~m}$. The distance of the SLM position from the center of the runway was measured using a standard measuring tape before the arrival of the craft. Measurements were taken during landing and taking-off for three consecutive days.

The same procedure was repeated for train noise data gathering at the Ilorin Railway Station. Permission was sought and granted by the Senior Station Master for the measurements to be carried out. Locomotives makes the most noise when the engine revves or horns. A schedule of

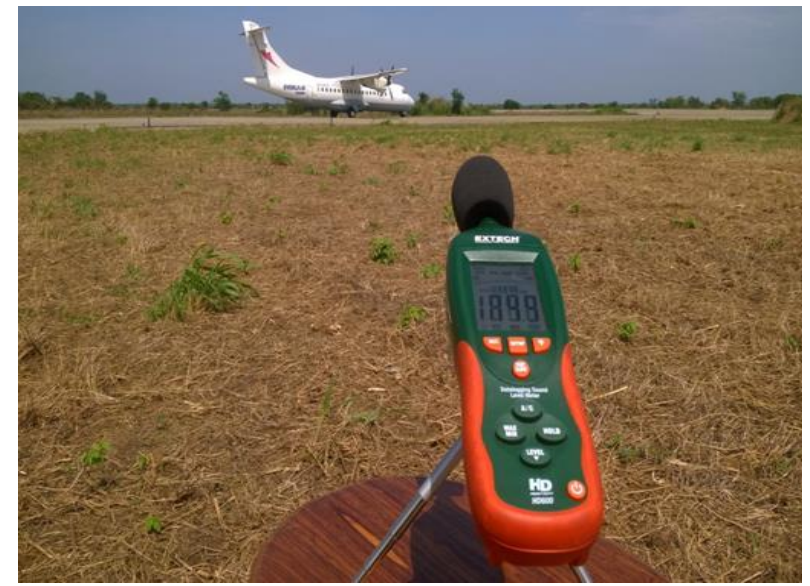

Plate 1: Instrument Set-up at Airport

passenger and freight trains was obtained from the Station Superintendent. A decision was taken to take measurement of the freight trains in order to reduce undesirable human noise that will always accompany passenger trains. The noise measurements were taken from a diesel fueled locomotive engine with an average of 21 wagons. Again, the Meter was set up at a known distance on the platform but very close to the tracks.

The noise from road transportation was measured at two locations based on reconnaissance surveys. These are the Tipper Garage roundabout and at Eiyenkorin, a settlement just outside Ilorin town. The former was chosen because of its high vehicular traffic and the noise generated are from slow moving vehicles. The latter was chosen to record noise produced by fast moving vehicles. These locations are shown in Figure 1. Measurements were taken between 8 - 10am daily, representing the peak vehicular period, for three consecutive working days and the average value was used for the analysis. The choice of the time was based on reconnaissance survey and literature. A detailed traffic count was not carried out because this will have little or no effect on the results since the summation of noise from different sources is not necessarily algebraic. The measurements were done with the assistance of traffic wardens and the police. The meter was set up at suitable positions near the roads and distance and noise data were taken. In all cases, there were no obstacle between the meter and the noise sources.

\section{A. Estimation of Sound Pressure Level}

The equivalent continuous noise level (Leq) is the sound pressure level of a steady sound that has, over a given period, the same energy as a fluctuating sound in question. It is calculated using equation 1 (Zhang \& Pei, 2016).

$$
\begin{aligned}
& L_{e q}=10 \log \sum_{i=t}^{i=n}\left(10^{L / 10}\right)(t i) \\
& \text { where, } \\
& \begin{array}{l}
L_{e q}=\text { equivalent noise level dB(A) } \\
n=\text { total number of sample taken } \\
L=\text { noise level in dB(A) of its sample } \\
t i \quad=\text { fraction of total sample time }
\end{array}
\end{aligned}
$$


Table 1: Summary of maximum, minimum, equivalent and average noise levels In Ilorin International Airport.

\begin{tabular}{lccccccc}
\hline & \multicolumn{7}{c}{ Days } \\
\hline Noise level dB(A) & 1 & & 2 & & 3 & \\
& & Landing & Taking Off & Landing & Taking Off & Landing & Taking Off \\
Maximum sound level & 87.80 & 85.30 & 64.00 & 83.90 & 79.30 & 76.40 \\
Minimum sound level & 48.60 & 50.40 & 39.50 & 40.90 & 46.00 & 58.50 \\
Equivalent noise level & 76.27 & 71.95 & 60.74 & 72.30 & 71.98 & 69.24 \\
Average noise level & 71.27 & 69.64 & 58.50 & 68.69 & 68.95 & 70.05 \\
Distance from runway (m) & & 18.2 & & & 23.5 & & 21.3 \\
\hline
\end{tabular}

Table 2: Summary of maximum, minimum, equivalent and average noise levels In Ilorin Railway Station.

\begin{tabular}{lcc}
\hline & \multicolumn{2}{c}{ Train Engine Activity } \\
\hline Noise level dB(A) & Revving of Engine & Train movement +Horn \\
Maximum sound level & 78.40 & 114.50 \\
Minimum sound level & 63.50 & 46.20 \\
Equivalent noise level & 73.22 & 98.62 \\
Average noise level & 71.98 & 89.10 \\
Distance $(\mathrm{m})$ & 5.4 & 5.4 \\
\hline
\end{tabular}

The average noise level from the data obtained during the work is expressed as (Zhang \& Pei, 2016);

$L_{n}=20 \log \sum_{i=1}^{i=N}\left(10^{L / 20}\right)(1 / N)$

where,

$L_{n}=$ average noise level

$N=$ number of measurements

$L=$ noise level in $\mathrm{dB}(\mathrm{A})$ of ith measurement

The sound-distance relationship applied is in eqn (3). For sound levels higher than the regulated value, this was used to determine the distance of the permissible sound levels using the reference distance, maximum noise level and the standard noise level of $85 \mathrm{dBA}$.

Sound level at any location from the source is given by (Singal, 2005):

$L_{2}=L_{1}-\left|20 . \log \left(\frac{r 1}{r 2}\right)\right|$

Distance of permissible sound level from eqn (3);

$r_{2}=r_{1} \cdot 10^{(|L 1-L 2| / 20)}$

where

$L_{1} \quad=$ Sound level at reference distance

$L_{2} \quad=$ Sound level at another distance

$r_{1}=$ Reference distance from sound source

$r_{2}=$ Another distance from sound source

\section{B. Noise perception}

The perception of people around the study areas to transportation noise was also evaluated using the Bayesian Theorem. This is a statistical theory which describes the probability of an event based on prior knowledge of conditions that might be related to the event. For this experiment, the variables used was the residency status of the people. Baye's Theorem is stated as presented in eqn (5) (Cornfield, 1967):

$$
P(A \mid B)=\frac{P(B \mid A) \cdot P(A)}{\mathrm{P}(\mathrm{B})}
$$

where

$\mathrm{A}$ and $\mathrm{B}$ are events and $\mathrm{P}(\mathrm{B}) \neq 0$
$\mathrm{P}(\mathrm{A})$ and $\mathrm{P}(\mathrm{B})=$ Probabilities of observing $\mathrm{A}$ and $\mathrm{B}$ without regard to each other

$\mathrm{P}(\mathrm{A} \mid \mathrm{B})=\mathrm{A}$ conditional probability of observing event $\mathrm{A}$ given that $\mathrm{B}$ is true

$\mathrm{P}(\mathrm{B} \mid \mathrm{A})=\mathrm{A}$ conditional probability of observing event $\mathrm{B}$ given that $\mathrm{A}$ is true

Baye's theorem helps in using a known outcome to predict the sequence of events leading up to that outcome. Questionnaires were administered at the different locations and the results were used to evaluate the noise perception. The questions covered residency, demography and noise perception.

\section{RESULTS AND DISCUSSION}

The outcome of the measured sound pressure levels for landing and taking off of aircrafts is summarized in the Table 1. The maximum and minimum values were obtained by direct measurements while the equivalent and average noise levels were calculated using Equations 1 and 2. The maximum sound level of $87.8 \mathrm{dBA}$, which is above the international standard tolerable limits of $85 \mathrm{dBA}$ was obtained from measurements taken $18.2 \mathrm{~m}$ from the runway, being the permissible distance to set up the measuring instrument as allowed by Airport management.

Table 2 shows the results of the maximum and minimum sound level pressure measurements, as well as the equivalent noise levels and average noise levels generated from the Ilorin railway station during revving of the engine, movement and horning of the locomotive freight train engine.

The noise level when the locomotive engine was just revving was within the acceptable limits of tolerable noise but goes well above the limit during movement and horning. Figures 2 and 3 show the difference in sound levels obtained at the train station. The graphs are indicative of the random noise variation of the revving locomotive and the stepwise noise variation due to motion and horning. 


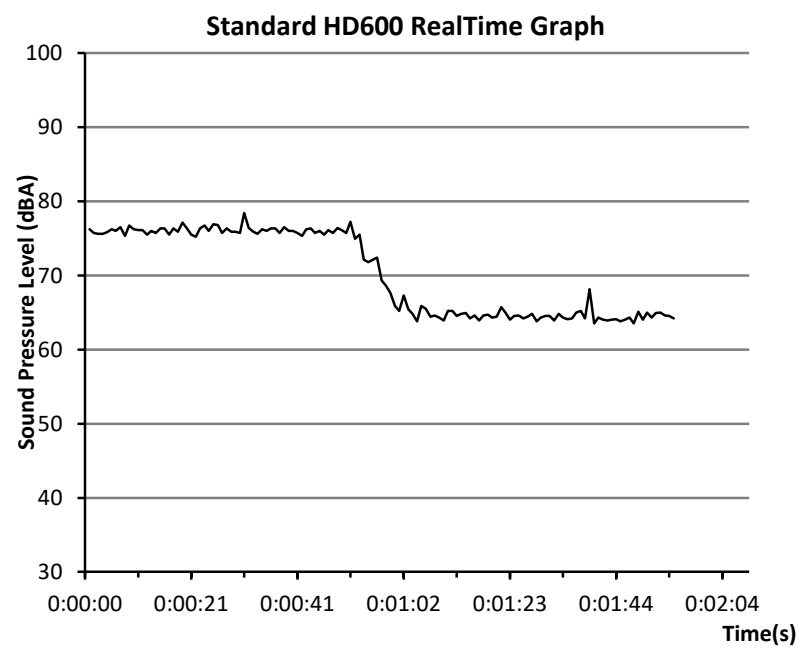

Figure 2: Sound levels of train engine during revving.

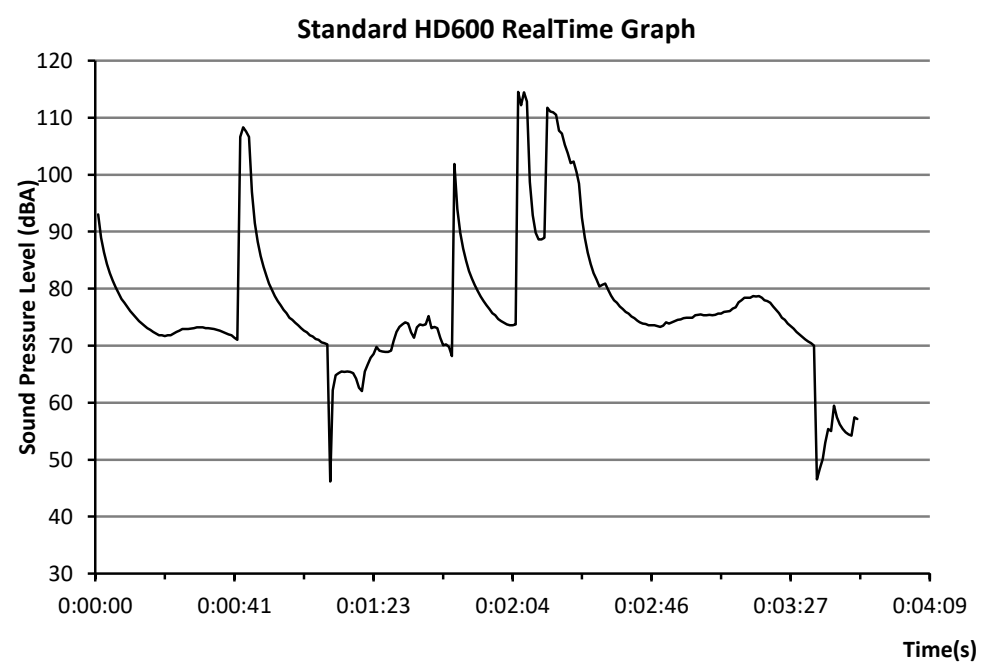

Figure 3: Sound levels of train engine during train movement and horning.

Table 3: Summary of maximum, minimum, equivalent and average noise levels at Eiyenkorin and Tipper Garage roads.

\begin{tabular}{lcc}
\hline & \multicolumn{2}{c}{ Road Location } \\
\hline Noise level dB(A) & $\begin{array}{c}\text { Eiyenkorin } \\
\text { Road }\end{array}$ & $\begin{array}{c}\text { Tipper Garage } \\
\text { Roundabout }\end{array}$ \\
Maximum sound level & 89.00 & 93.30 \\
Minimum sound level & 47.00 & 48.30 \\
Equivalent noise level & 62.94 & 73.23 \\
Average noise level & 60.09 & 71.11 \\
Distance from road & 8.74 & 5.8 \\
Centre (m) & & \\
\hline
\end{tabular}

This means that at a distance of $25.12 \mathrm{~m}$ from the runway during landing, the sound level is considered safe over a specific period of time. This is considered as a low noise dose as the duration of exposure is usually a few minutes. The process was repeated for Aircraft take-off, movement and horning of locomotive engine, vehicular traffic at Eiyenkorin and that at Tipper garage area. The obtained distances where sound level is considered safe were $18.84 \mathrm{~m}, 161.21 \mathrm{~m}$, $13.85 \mathrm{~m}$ and $15.08 \mathrm{~m}$ respectively. The highest noise level was exceding level to humans is calculated for noise values Equations 3 and 4 .

For Landing of aircraft at Ilorin International Airport

$\mathrm{L}_{1}=87.80 \mathrm{~dB}(\mathrm{~A}), \mathrm{L}_{2}=85 \mathrm{~dB}(\mathrm{~A}), \mathrm{r}_{1}=18.2 \mathrm{~m}$

$$
\begin{aligned}
& r_{2}=r_{1} \cdot 10^{(|L 1-L 2| / 20)} \\
& r_{2}=25.12 \mathrm{~m}
\end{aligned}
$$

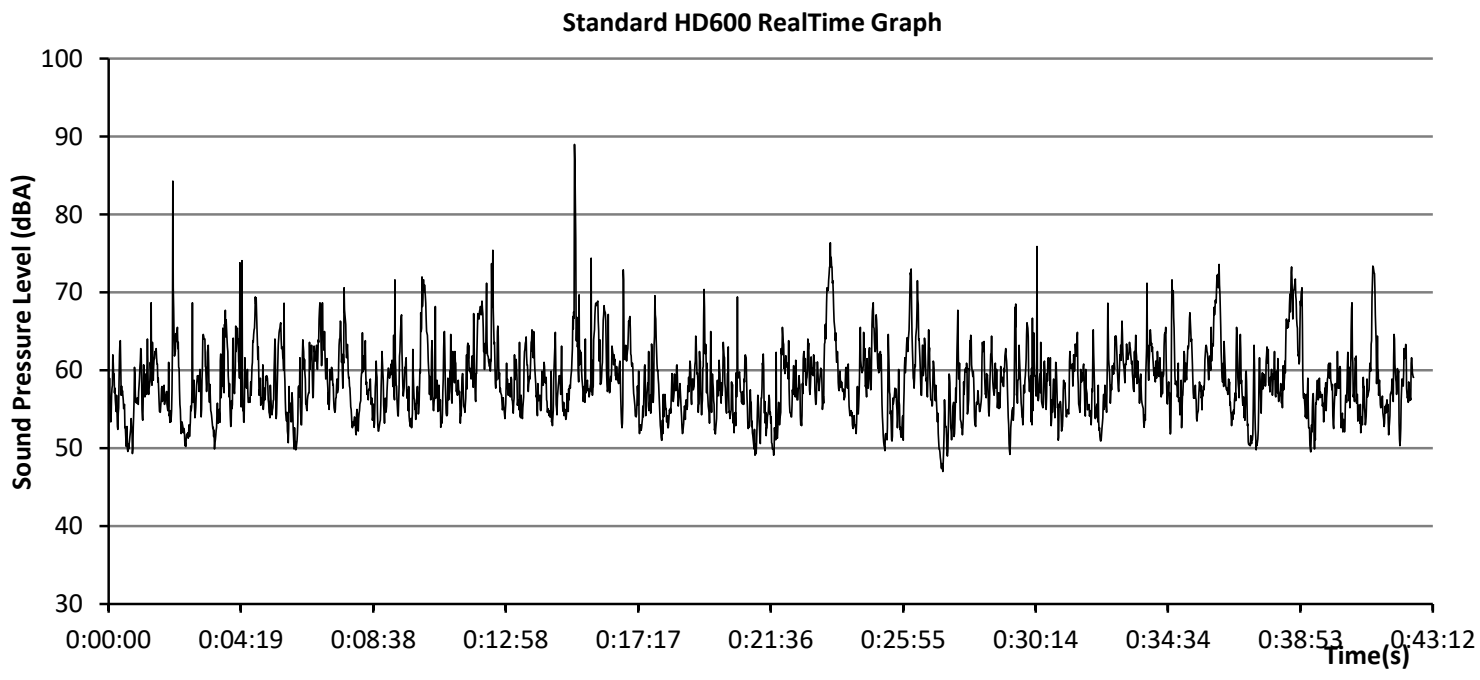

Figure 4: Sound Levels for Road Transportation Systems at Eiyenkorin (Trunk) Road. 


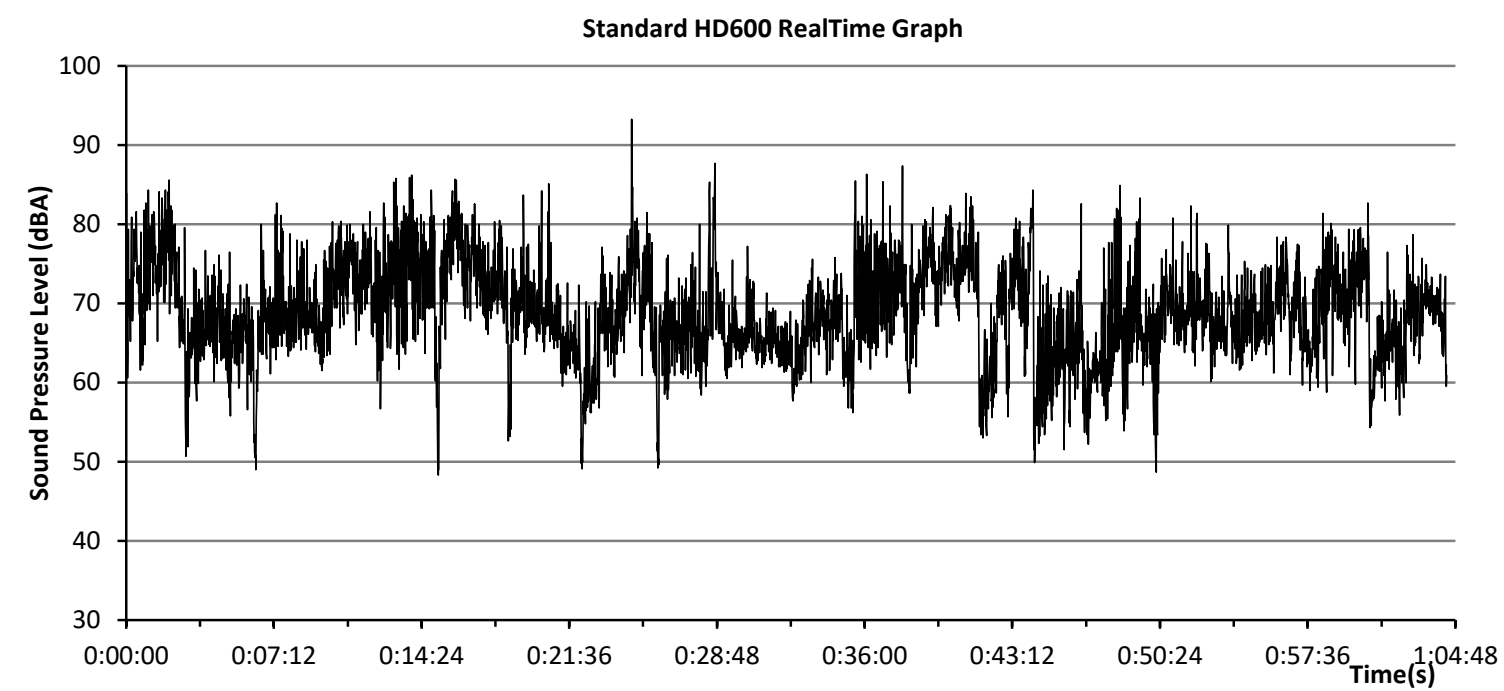

Figure 5: Sound Levels for Road Transportation Systems at Tipper Garage Roundabout.

produced during the horning of the locomotive engine. While the Tipper Garage area of the town cannot be said to be free of reflecting objects, there were no obstacles between the SLM and the noise sources.

\section{Noise Perception Survey Results}

A total of eighty questionnaires administered across four locations. $65 \%$ of the respondents were males. Care was taken to ensure that the respondents were residents or shop owners in the concerned areas and not passers-by. Measured noise levels at all the locations have shown the extent of noise generated in the areas. However, a study of the noise perception by the residents was estimated from the results obtained from the questionnaire administration using the Bayesian probability theorem. For the Airport, Train Station and Tipper Garage which represents aircraft, train and internal vehicular traffic, noise perception by residents was $100 \%$. However, for the fast moving traffic at Eiyenkorin, the probability of noise perception obtained was 0.9 (90\%). $60 \%$ of the respondents were residents of the area while $40 \%$ were just shop or business owners.

The posterior probability of noise perception for the residents of the area for residents and non-residents was 0.93 and 0.86 , respectively. This means that the maximum measured noise from the transportation systems is not only above the permissible standard, it is also perceived to be so. It is also to be noted that the average ambient noise at the Ilorin International Airport resulted in $45.63 \mathrm{~dB}(\mathrm{~A})$ while that of the Ilorin Railway station had an average ambient noise of 57.3 $\mathrm{dB}(\mathrm{A})$. This indicates that there is a higher background noise at the Railway Station as compared to the Airport. However, as noise measurements are not added algebraically, the ambient noise becomes less significant compared to the noise generated by the various transport modes.

\section{CONCLUSION}

This study was explicitly carried out to determine the noise intensity from air, rail and road transportation systems in Ilorin, as well as comparing the results obtained with the universally accepted upper noiseless value of $85 \mathrm{~dB}(\mathrm{~A})$. The higher limits of noise produced at all the locations were above this value. Most residents also perceived the noise as unacceptable. It is therefore safe to conclude that irrespective of the source, transportation noise may be a public nuisance in Ilorin and most urban areas in Nigeria. It pollutes the environment and exposes community residents to serious hazards resulting from noise.

The study also established distances in which the sound level is safe over a specific period of time for each of the studied noise sources. These are of $18.84 \mathrm{~m}, 161.21 \mathrm{~m}, 13.85 \mathrm{~m}$ and $15.08 \mathrm{~m}$ for aircraft take-off, movement and horning of railway locomotive engine and vehicular traffic inside and outside town respectively. However, at some safe distance as calculated, no harm is caused. From the foregoing, residential buildings, academic areas and hospitals should not be located too close to sources of transportation noise. The need for the enforcement of relevant noise control laws should also be pursued and proper maintenance of transport vehicles should be emphasized.

\section{REFERENCES}

Abolarin, T. S. (2012). Identification of major noise donors, a sure way to abating noise. Mechanical Engineering Department, Kwara State Polytechnic Ilorin, Nigeria. Proc. ICCEM (2012): 13 - 20.

Ajadi, B.S.; A. Adeniyi and M. T. Afolabi. (2011). Impact of Climate on Urban Agriculture: Case Study of Ilorin, Nigeria. Global Journal of Human Social Science, 11 (1): $24-30$.

Anomohanran, O. (2013). Evaluation of environmental noise pollution in Abuja, the capital city of Nigeria. 
International Journal of Research and Reviews in Applied Sciences, 14(2): $470-476$.

Aremu, A.; H. Saka and A. Adedeji. (2012). Assessing the Noise Pressure Level in Libraries' Study Rooms in Nigeria-A Tropical Region. Epistemics in Science, Engineering and Technology, 2 (4): 139-151.

Basner, M.; U. Müller and E. M. Elmenhorst. (2011). Single and Combined Effects of Air, Road, and Rail Traffic Noise on Sleep and Recuperation. Sleep, 34 (1): 11-23.

Carrier, M.; P. Apparicio; A. M. Séguin, and D. Crouse. (2016). The Cumulative Effect of Nuisances from Road Transportation in Residential Sectors on the Island Of Montreal - Identification of the Most Exposed Groups and Areas. Transportation Research Part D: Transport and Environment, 46: 11-25.

Clark, C. and Stansfeld, S. A. (2007). The Effect of Transportation Noise on Health and Cognitive Development: A Review of Recent Evidence. International Journal of Comparative Psychology, 20 (2): 145 - 158.

Cornfield, J (1967). Bayes Theorem, Review of the International Statistical Institute, 35 (1): 34 - 49.

Department for Environment, Food and Rural Affairs (DEFRA) 2010: Noise Policy Statement for England, Published by the UK Department for Environment, Food and Rural Affairs and available online at http://www.defra.gov.uk/environment/quality/noise/ accessed on July 11, 2018.

Gershon, R. R.; R. Neitzel; M. A. Barrera and M. Akram. (2006). Pilot Survey of Subway and Bus Stop Noise Levels. Journal of Urban Health, 83(5), 802.

Ko, J. H.; S. I. Chang; M. Kim; J. B. Holt and J. C Seong. (2011). Transportation Noise and Exposed Population of an Urban Area in the Republic of Korea. Environment International, 7(2): 328-334.

Luqman, Y. A.; A. G. Rowland; Y. Zhang and O. Z. Umar. (2014). Work Environment Noise Levels and Risk Locations in Two Selected Commercial Areas in Ibadan, Nigeria. Global Journal of Medical Research, 13(6): 24 - 34.

Mansouri, N.; M. Pourmahabadian and $M$. Ghasemkhani. (2006). Road Traffic Noise in Downtown Area of Tehran. Journal of Environmental Health Science \& Engineering, 3(4): 267-272.

Mayer M. (2018). What is the Decibel Level of a Jet Plane? Available online at Sciencing.com/decibel-level-jetplane-5375252.html. Accessed on June 30, 2018.
National Population Commission (2006). 2006 Population and Housing Census of the Federal Republic of Nigeria.

National Environmental Standards and Regulations Enforcement Agency (NESREA) (2009). National Environmental Noise Standards and Control Regulations, 2009. Federal Republic of Nigeria Official Gazette, Vol. 96, No. 67, S.I. No. 35, FGP 104/102009/1,000 (OL 60). The Federal Government Printer, Nigeria.

Obisung, E. O.; A. O. Akpan, and U. E. Asuquo. (2013). Aircraft Noise Nuisance in Nigeria a Social and Acoustical Survey. International Journal of Engineering Research and Applications, 3 (1): 680-692.

Occupational Safety and Health Administration (OSHA) (1996). Requirements of the Occupational Noise Exposure Standard With Regards to Hearing Protectors, Standard No. 1910.95, Published by the United States Department of Labour, Washington, USA.

Omubo-Pepple, V. B.; M. A. Briggs-Kamara and I. Tamunobereton-ari. (2010). Noise Pollution in Port Harcourt Metropolis: Sources, Effects and Control. The Pacific Journal of Science and Technology, 11 (2): 592-600.

Oyedepo, O. S. and Saadu, A. A. (2010). Evaluation and Analysis of Noise Levels in Ilorin Metropolis, Nigeria. Environmental Monitoring and Assessment, 160(1-4), 563.

Pathak, V.; B. D. Tripathi, and V. Kumar-Mishra. (2008). Evaluation of Traffic Noise Pollution and Attitudes of Exposed Individuals in Working Place. Atmospheric Environment, 42(16): 3892-3898.

Saadu, A. A.; R. O. Onyeonwu; E. O. Ayorinde, and F. O. Ogisi. (1996). Community Attitudinal Noise Survey and Analysis of Eight Nigerian Cities. Applied Acoustics, 49(1): 49-69.

Singal, S. P. (2005). Noise Pollution and Control Strategy, Narosa Publishing House PVT Limited, New Delhi, India.

Yilmaz, H., \& Ozer, S. (2005). Evaluation and Analysis of Environmental Noise Pollution in the City of Erzurum, Turkey. International Journal of Environment and Pollution, 23(4): 438-448.

Zhang, H. and Pei, Y. (2016). Simulation-Based Prediction of Equivalent Continuous Noises during Construction Processes, International Journal of Environmental Research and Public Health, 13: 818 - 830. 